\title{
O DIÁLOGO REPÓRTER-FONTE E A INFLUÊNCIA DO PÚBLICO INSTITUÍDO
}

\author{
Renato Essenfelder ${ }^{*}$
}

\begin{abstract}
Resumo: Situada em pleno continuum entre as modalidades escrita e falada da língua, a entrevista, em suas variadas formas, é um tipo de interação especial, na qual a noção de publicidade do discurso, gerada para ampla divulgação, substitui o caráter mais "intimista" dos diálogos. Em razão disso, os interlocutores de uma entrevista, especialmente no caso da jornalística, precisam se preocupar com questões como a preservação da face diante de um público ausente no momento da enunciação e com o atendimento das expectativas e anseios dessa audiência genericamente delineada. Este estudo mostra, com base em uma entrevista jornalística real, que estratégias entrevistado e entrevistador usam para modular e replanejar seus discursos de modo a satisfazer seus pressupostos de uma destinatário terceiro imaginário.
\end{abstract}

Palavras-chave. Análise da conversação; diálogo; trílogo; interação.

\section{Introdução}

Imaginemos o seguinte exemplo hipotético: pela manhã, o prefeito de uma grande cidade concedeu entrevista a um jornal de elite. Falou longamente sobre segurança pública e medidas que serão "implementadas para coibir o aumento nas taxas de criminalidade do município". Pela tarde, falando ao mesmo repórter, desta vez representando uma rádio popular, o prefeito respondeu a perguntas semelhantes dizendo que vai "pôr mais policiais nas ruas" para "prender e assustar os bandidos".

A mudança no discurso do prefeito nessa situação imaginária ilustra um fenômeno concreto: a dinâmica das entrevistas em geral difere da de outras interações verbais mais espontâneas porque nelas o tom "intimista" do diálogo casual é substituído pela noção de publicidade do discurso, ou seja, nas entrevistas o dizer é disseminado na sociedade de forma freqüentemente incontrolável - particularidade que gera, por si só, significativas diferenças nos momentos de preparação e execução do discurso. Assim, de acordo com o público que os interlocutores imaginam prototípico do meio de comunicação em questão, mudarão linguagem, postura e até mesmo a carga informativa do processo comunicativo.

É a presença desse outro invisível, do público leitor/ouvinte/telespectador, que condiciona a interação verbal (e a não-verbal também, no caso de gestos e expressões ensaiadas para causar certos efeitos no público) nas entrevistas.

As manifestações do outro ao longo do discurso interativo são justamente o objeto deste estudo, que parte de uma amostra de entrevista telefônica gravada para

\footnotetext{
* Mestrando do Programa de Pós-Graduação em Língua Portuguesa, da Pontifícia Universidade Católica de São Paulo.
} 
investigar como o terceiro invisível - audiência ou público construído a partir de inferências e traços genéricos - aparece nas entrelinhas de um tipo específico de interação, a entrevista jornalística.

Direcionado antes à massa do que a um uso particular, o relato jornalístico deixa mais acentuadas as marcas de preocupações como a preservação da face, a comunicação clara de determinadas idéias e ideais e a sedução ou convencimento do leitor/ouvinte/telespectador. Se aparentemente o destinatário direto da entrevista é o próprio entrevistador, pretendemos mostrar que seu papel na construção do discurso do entrevistado é menor, pois é a audiência, destinatário a princípio indireto, que de fato orienta a preparação e a execução das falas.

\section{Notícia do corpus}

O diálogo coletado para análise tem a peculiaridade de ter sido originalmente concebido para fins jornalísticos. Trata-se de uma entrevista realizada por repórter do jornal Folha de S.Paulo com uma figura pública, um Secretário Municipal da Prefeitura de São Paulo. A gravação tem um total de 27 minutos. Embora o corpus seja relativamente pequeno, dadas as suas especificidades (informante e documentador acostumados a conduzir/conceder entrevistas; meio de comunicação de massa de grande circulação - portanto, com numerosos receptores delineados; tema de apelo público), é fértil em manifestações do efeito da audiência sobre o discurso.

A entrevista foi gravada por via telefônica a pedido do próprio entrevistado. Para efeito desta análise lingüística, que não considera os signos não-verbais da conversação, o meio escolhido se mostrou satisfatório, já que nas conversações telefônicas "todos os problemas devem ser resolvidos verbal e explicitamente" (MARCUSCHI, 2001, p. 54). Assim, mensagens de não-entendimento e pedidos de confirmação do já-dito são manifestos verbalmente em vez de gestualmente no corpus, o que se mostrou positivo para esta análise.

A transcrição do evento comunicativo foi registrada no sistema ortográfico padrão, seguindo rigorosamente o modo de enunciação. As normas de transcrição foram as mesmas adotadas pelo Projeto NURC/SP (Norma Urbana Culta de São Paulo), da Universidade de São Paulo (USP) (vide Anexo B).

Para efeito de análise, escolhemos o trecho inicial (primeiros cinco minutos) da conversação, que tem as seguintes características:

1 - o entrevistador deixa o entrevistado falar mais livremente, como forma de "quebrar o gelo" e conquistar a simpatia deste para revelações futuras, ao longo da entrevista;

2 - $\quad$ as intervenções, portanto, do entrevistador são em sua maioria com marcadores de apoio e monitoramento do ouvinte, do tipo ahn ahn;

3 - é quando entrevistador e entrevistado procuram uma linguagem mais adequada de tratamento recíproco (o "tom ideal") e em relação à audiência, ajustando a equação informação/argumentação/sedução que definirá se a interação transcorrerá em clima contratual ou polêmico.

É também nesses primeiros minutos que aparecerão as formas mais interessantes de manifestação de um público indireto determinando os rumos da conversação, como veremos posteriormente. 


\section{Considerações teóricas}

A entrevista é uma modalidade muito especial de interação verbal. Tem características que a afastam de um uso oral prototípico da língua, como no caso das conversações espontâneas, pois envolve um certo nível de pré-planejamento. Ao mesmo tempo, contudo, mantém diferenças relevantes em relação à língua escrita, pois tem concepção oral e uma complexa relação de concomitância (na coleta de dados, etapa do diálogo entre entrevistador e entrevistado) e não-concomitância (etapa da edição no suporte gráfico ou audiovisual) temporal que a aproxima da língua falada. Podemos dizer, portanto, que se situa dentro do continuum língua falada/língua escrita, situada ora mais próxima do gênero falado típico - caso das entrevistas pessoais e no rádio ou televisão -, ora vizinha ao gênero escrito, como nas entrevistas de jornal e revistas, nas quais o discurso da fonte é editado e retrabalhado quantas vezes forem necessárias até a obtenção de um produto final coerente com as intenções do meio de comunicação em questão. (MARCUSCHI, 2003).

Quando citamos a palavra entrevista, é comum imaginarmos de imediato um cenário tipicamente jornalístico, com repórter e determinada fonte de informação como protagonistas. Mas o estereótipo é enganador. O gênero entrevista faz, em realidade, parte da vida de todos nós, e se manifesta, talvez com menos glamour, cotidianamente. Quando pedimos informações sobre um pacote turístico, novo lançamento da indústria automotiva ou durante uma sabatina de emprego estamos reeditando, informalmente, um conceito mais amplo de entrevista.

A entrevista é uma atividade em que, não somente pessoas ligadas à área de comunicação, como os jornalistas, mas todos nós, de uma forma ou de outra, estamos envolvidos, quer como entrevistadores, quer como entrevistados. Seu objetivo é sempre o inter-relacionamento humano, mas os direitos dos participantes não são os mesmos, pois o entrevistador faz as perguntas e oferece, em seguida, o turno ao entrevistado. Na verdade, as relações de poder entre eles deixa-os em diferentes condições de participação no diálogo.

(FÁVERO, 2000, p. 79-80)

Em realidade, como veremos adiante, é lícito dizermos desde já que todos nós sempre estamos, de alguma forma, participando de entrevistas: se não como seus protagonistas, como o público destinatário (in)direto que influencia o discurso de ambas as partes, no caso de entrevistas concebidas para ampla divulgação (jornalísticas, de Ciências Humanas etc.).

Longe do mundo das câmeras e microfones, então, promover ou participar de uma entrevista significa tão somente interagir, obter informações, disseminar um discurso particular na sociedade.

Em suas várias aplicações, a entrevista é uma técnica de interação social. Por meio dela, busca-se uma interpenetração informativa que visa a quebrar isolamentos sociais, grupais, individuais; pode ainda servir à pluralização de vozes e à distribuição democrática da informação. Em seus diversos usos nas Ciências Humanas, constitui sempre um meio cujo objetivo fundamental é o inter-relacionamento humano. Enquanto gênero jornalístico, a entrevista pode ser definida como uma técnica eficiente na obtenção de respostas pré-pautadas por um questionário. (FÁVERO; ANDRADE, 1998, p. 154-155) 
As particularidades do gênero entrevista em relação ao diálogo comum entre duas pessoas residem principalmente no fato de haver uma pauta ou roteiro, geralmente bem definidos, de assuntos a tratar - da qual não convém se desviar, sob pena de terminar a interação sem obter o conhecimento de início visado. Segundo Fávero (2000, p. 83) "a entrevista, porém, constitui um tipo especial de texto falado porque o planejamento existe da parte do entrevistador e pode existir também, em certos casos, da parte do entrevistado, diminuindo, dessa forma, marcas da oralidade".

De fato, se consideramos a questão do planejamento como central na diferenciação entre língua falada e língua escrita, reforçamos a hipótese de a entrevista pairar em pleno continuum entre os extremos dessas modalidades. Segundo Rodrigues:

[...] duas outras características da língua falada em oposição à língua escrita resultam da diferença básica entre as condições de produção de uma e outra: tendência para o não planejamento e envolvimento da língua falada e planejamento e distanciamento (ou não envolvimento) da língua escrita. O texto falado apresenta marcas linguísticas evidentes de seu planejamento passo a passo, como texto construído pelos locutores envolvidos na conversação, de que resultam frases mais fragmentadas do ponto de vista sintático. $O$ texto escrito não deixa marcas do processo de planejamento: ele se apresenta como um todo coeso, acabado, com frases mais densas e sintaticamente mais complexas. Por outro lado, o envolvimento constitui característica da língua falada, entendido não só o envolvimento dos interlocutores com o assunto da conversa, mas também entre eles mesmos. (RODRIGUES, 2003, p. 36)

Assim, a inscrição temporal da entrevista pende para o extremo da modalidade escrita da língua, pois compreende etapas bem marcadas e não-concomitantes, a saber:

1 - Pauta, pesquisa e planejamento: antes de se encontrar com seu interlocutor, o entrevistador usualmente pesquisa a fundo o tema que pretende abordar, identificando tópicos oportunos para a condução do diálogo. Saliente-se que sem a etapa de pauta, pesquisa e planejamento a entrevista corre sérios riscos de naufragar, de não chegar a lugar nenhum, pois seu caráter assimétrico concede ao entrevistador o direito de definir o tema e conduzi-lo da maneira que considerar mais adequada para a plena realização da pauta, enquanto ao entrevistado cabe manter a palavra - ou turno - por mais tempo, com vistas ao esclarecimento das questões colocadas.

2 - Execução: é o momento da entrevista propriamente dita, quando entrevistador e entrevistado encontram-se face a face (ou via mídias como telefone e internet) para interagir.

3 - $\quad$ Edição: trabalho solitário do entrevistador, durante o qual são pinçadas as falas mais relevantes do entrevistado com vistas a comprovar ou refutar determinada tese que constava da pauta inicial. Aí o caráter do trabalho é mais próximo do prototípico da língua escrita, pois envolve planejamento cuidadoso e a possibilidade de apagamento de marcas de hesitação, monitoramento, contestação e assentimento, entre outras.

Segundo Fávero e Andrade (1998, p. 158), “em relação aos demais textos conversacionais, a entrevista se distingue por três aspectos: o número de participantes envolvidos em sua organização; o caráter assimétrico da interação; o planejamento e o tempo de elaboração." Já abordada a questão do planejamento e tempo de elaboração (da pesquisa à edição), cabe delongarmo-nos um pouco mais sobre os demais tópicos. 
A simetria e assimetria na interação tipo entrevista são determinadas pelos papéis dos interlocutores, que são invariavelmente distintos. Conforme já mencionamos, o entrevistador dá o tema e o conduz, enquanto o entrevistado divide seu conhecimento sobre o tópico. Além disso, cabe também a quem propôs a entrevista - o entrevistador definir seu caráter: será contratual ou polêmico? Conforme o efeito desejado, o tipo de público e informação visados, uma ou outra opção se mostrará mais adequada, mais eficiente. É o entrevistador que, geralmente, tem o poder de mudar de tópico e encerrar a conversação, de acordo com o seu desejo.

Não se pode esquecer, entretanto, que o conceito de assimetria está também subordinado aos papéis sociais desempenhados pelos interlocutores e a suas características pessoais, seus papéis pessoais. Notoriamente, certos entrevistadores superam o próprio entrevistado em termos de prestígio social. No jogo das relações de poder sociais, é inadmissível imaginar um entrevistador de renome, como Jô Soares ou Marília Gabriela, por exemplo, mantendo uma entrevista simétrica com um interlocutor anônimo, ainda que este detenha mais conhecimentos do que aqueles. Da mesma forma, um estudante universitário simplesmente não conseguirá conduzir uma entrevista com personalidades de destaque (a título ilustrativo, imagine um aluno de Letras entrevistando uma figura como o senador Antônio Carlos Magalhães), salvo raríssimas exceções, quando os papéis pessoais - entrevistador arguto e audaz e personalidade tímida e humilde - se sobrepuserem aos sociais.

Já a organização interacional da entrevista prevê um esquema plural de relações comunicativas:

Três diálogos são instaurados durante a atividade:

- entrevistador e entrevistado;

- entrevistado e audiência (público: leitor, ouvinte, telespectador);

- entrevistador e audiência. (FÁVERO; ANDRADE, 1998, p. 156)

Destacamos o papel central que a audiência exerce sobre a entrevista, dirigindo sua forma (contratual ou polêmica), apresentação (nível lexical, polidez e impolidez, formalidade e informalidade) e até mesmo seu conteúdo - em última análise, a entrevista deve satisfazer às dúvidas e anseios do público visado, e não dos interlocutores diretamente envolvidos na comunicação. "Durante as entrevistas, os participantes não apenas expressam suas idéias e opiniões, trocam informações, mas também - ao cumprir seus papéis - constróem juntos o texto, buscando atuar sobre o outro e sobre a audiência" (FÁVERO; ANDRADE, 1998, p. 159).

A maioria dos trabalhos inscritos no âmbito da Análise da Conversação se debruça, tradicionalmente, sobre interações verbais entre duas pessoas (sejam elas informante e documentador ou apenas dois informantes), seguindo a fórmula ababab de pares conversacionais. $\mathrm{Na}$ análise das entrevistas, contudo, faz-se necessário ir além do par questionador/fonte para investigarmos o trílogo que se instaura nessa interação. As múltiplas relações interacionais da entrevista envolvem três atores distintos e bem marcados. Podemos esquematizá-las da seguinte forma, como mostrado no Quadro 2: 


\section{LOCUTOR 1}

LOCUTOR 2

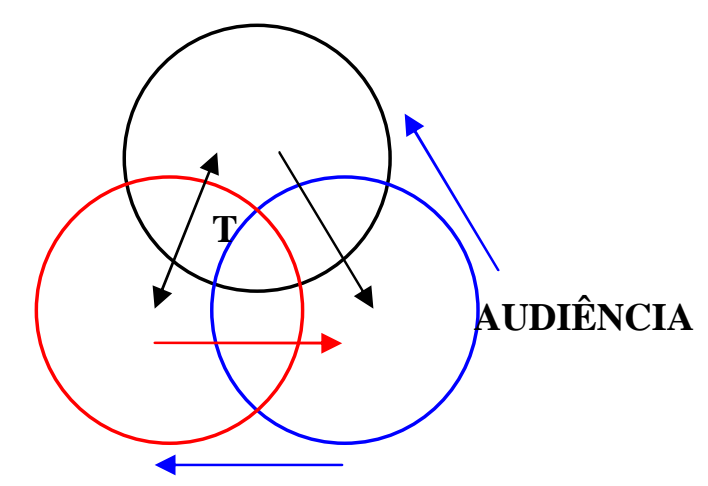

No qual:

1 - locutor 1 e locutor 2 compõem um grupo interacional comum pelo qual trocam idéias e opiniões durante o evento discursivo propriamente dito;

2 - locutor 1 e audiência mantém uma relação destinador-destinatário na qual a audiência é, durante o evento comunicativo, passiva, o aparente destinatário indireto;

3 - locutor 2 e audiência mantém uma relação destinador-destinatário semelhante, na qual a audiência é também aparente destinatário indireto;

4 - audiência mantém com os locutores 1 e 2, fora do evento interativo da entrevista propriamente dito, uma relação de condicionamento do discurso. Como a audiência é o motivo da entrevista, orienta, dessa forma, as falas, de forma a preencher as expectativas pressupostas pelos interlocutores diretos.

5 - No espaço dinâmico do trílogo (T), no qual se sobrepõem locutores e audiências, os interlocutores tentam satisfazer ao público, que busca ser colaborativo na medida que devidamente preenche as lacunas informativas e de conhecimento de mundo manifestas.

Tal esquema pressupõe um público heterogêneo, cujas demandas estão baseadas, pelos interlocutores, por inferências.

Nos debates, os participantes trabalham para construir junto ao telespectador um conhecimento comum, um consenso [...]. A argumentação [...] desenvolvese não para persuadir o outro debatedor, nem o mediador, mas o público ouvinte, telespectador que, por sua vez, também apresenta especificidades: não se trata de um público especial, de uma só classe social, de um só gênero, pois são eleitores o jovem ou o idoso, o assalariado ou o empresário, todo o público, enfim, precisa ser alvo da persuasão. (FÁVERO; AQUINO, 2002, p. 172-173)

Apesar de ser uma abstração nas entrevistas destinadas a uso público, a audiência têm um papel concreto.

Não se pode deixar de observar o papel desempenhado pela audiência como elemento propulsor de modificações na interação entre os participantes, já que a interação se desenvolve exatamente em função da terceira-parte e é em razão de não se perder esse aliado que se procede a reformulações ou reorientações temáticas. (FÁVERO; ANDRADE, 1998, p. 167) 
Nesse aspecto, a cenografia básica dos debates políticos televisionados é semelhante aos das entrevistas de comunicação em geral, pois todos atores com poder de fala têm em mente não convencer ao adversário ou mediador do encontro, mas sim ao público, à massa que os assiste sem, contudo, poder intervir no que é dito.

Nos debates [...] ainda que os elementos lingüísticos sejam indicativos de que o destinatário direto é o adversário político, este só o é aparentemente, pois, na realidade, o verdadeiro destinatário é o público. Assim, todos os destinatários têm papel importante na interação, não se podendo negligenciar nenhum deles, mesmo os indiretos. [...] De fato, é para o público que o debate é elaborado; ele condiciona sua existência; é por ele que os debatedores aceitam o convite e é a existência desse público e a imagem que os debatedores fazem dele que vai influenciar fortemente a forma como o discurso é elaborado (Doury, 1995: 227) ${ }^{1}$. Contudo, esse verdadeiro destinatário fica excluído, muitas vezes, do cenário onde o debate se realiza, parecendo, por essa razão, um destinatário indireto. Assim, pode-se dizer que esse público é indireto aparentemente; na realidade, ele é o principal - é a razão de existência do debate. (FÁVERO; AQUINO, 2002, p. 163;169)

Destinatário indireto aparente ou efetivamente direto, o fato é que o público têm o poder concreto de influenciar no discurso da entrevista. Conforme escreve KerbratOrecchioni (1990, p. 89) $)^{2}$, citado por Fávero (2000, p. 81), “todos os destinatários de uma mensagem, mesmo aqueles que o são indiretamente, desempenham um papel importante no desenvolvimento da interação".

Conforme sustenta Hilgert (2002, p. 89-90) é fato que:

[...] todo texto tem natureza dialogal. Essa característica se estende do texto escrito mais formal ao bilhete mais despretensioso; da fala solene da academia à conversação informal do cotidiano. A natureza dialogal determina, portanto, a produção de qualquer tipo de texto, uma vez que, conhecendo o destinatário, o destinador atribuirá características específicas a seu texto em função do interlocutor. Em outras palavras, o leitor e o ouvinte sempre serão participantes ativos na construção do texto. [...] Na construção do discurso do destinador as escolhas lingüísticas, as estratégias argumentativas, o estabelecimento dos implícitos, a explicitação maior ou menor de conhecimentos prévios e outros aspectos são co-determinados pelo destinatário.

\section{Estudo de caso}

A entrevista selecionada como corpus (Anexo A) deste estudo é iniciada por uma pergunta não-polêmica introdutória do tópico a ser desenvolvido:

1.Doc. $\quad-(\ldots)$ sobre as blitze para fechamento de bares após a uma hora... o/ eu queria saber o andamento se/se vai ser retomado isso agora com mais força

2.Inf. - Olha continua tendo o que está tendo agora::

3.Doc. hum?

\footnotetext{
${ }^{1}$ DOURY, Marianne. Duel sur la cinq: dilogue or trilogue? In: KERBRAT-ORECCHIONI, C.; PLATIN, C. (Org.). Le trilogue. Lyon: Universidade de Lyon 2, 1995. p. 224-249.

${ }^{2}$ Kerbrat-Orecchioni, C. Les intérations verbales. Paris: Armand Collin, 1990.
} 


\section{Inf. $\quad$ é que a gente deu uma modernizada no Psiu né? porque o Psiu não funcionava após as seis da tarde né? \\ 5. Doc. ahã}

Este procedimento de início do diálogo é comum nas entrevistas, que também podem ser iniciadas por um comentário opinativo que marque a posição ideológica do entrevistador. A estrutura Pergunta-Resposta (P-R) é, todavia, a mais comum de ser encontrada.

[...] o par dialógico P-R se configura como elemento imprescindível na organização do texto da entrevista, prestando-se a consolidar ou a modificar as relações entre os interlocutores (entrevistador, entrevistado, audiência), imprimindo um caráter vivo ao evento discursivo.

Constitui-se em estratégia que acumula efeitos, pois o entrevistador pode, por exemplo, formular um pedido de informação, confirmação ou esclarecimento, mas, ao mesmo tempo, servir-se da pergunta para mudar ou redirecionar o tópico, além de expor a face do outro participante. Vai, portanto, muito além do simples papel de obter informações. (FÁVERO, 2000, p. 96)

No caso, a pergunta (linha 1) oferece um tópico, que é prontamente aceito pelo entrevistado (linha 2). O trecho do corpus escolhido apresenta mais duas perguntas do documentador, destas vezes, contudo, elas apresentam função diferente da inicial (introdução e pedido de aprovação do tópico), focadas na confirmação e esclarecimento do que já foi dito pelo informante.

26.Inf. por exemplo a gente está fazendo cerca de dez... dez... va/vamos chamar assim de intervenção on-line ... que é uma pessoa reclama aí na HOra a equipe também a gente...

27.Doc. dez por noite isso?

28.Inf. dez por noite nesse caso que eu to te falando ( ) liga e vai na hora

29.Doc. $\quad$ Ahã $\quad$ ahã

O documentador pede, assim, que o entrevistado deixe mais clara a informação anterior "a gente está fazendo cerca de dez intervenções on-line" com o questionamento "dez por noite, isso?", já que a afirmação da fonte dava margem a dúvidas - e a ambigüidade ou dúvida são fenômenos indesejáveis, por excelência, nas entrevistas em geral e em especial nas jornalísticas. Adiante, tempos outro caso parecido:

40.Inf. então pra você ter uma idéia nas últimas duas semanas... a gente fechou 51 bares né? ...

41.Doc. $\quad$ ahn ahn

42.Inf. nos últimos dois fins de semana

43.Doc. então somando aí os que abrem depois da uma e os de

barulho... esses... esse número não?

44.Inf. $\quad$ os que abrem depois da uma né? ...

45.Doc. $\quad$ ah, certo

Novamente, a informação de que a Prefeitura de São Paulo fechou 51 bares à noite "na última semana", conforme diz o entrevistado (linha 40) precisa de um 
detalhamento posterior, pois no entender do repórter não fica claro se são 51 bares fechados só por causa de barulho excessivo (a lei manda autuar depois das 22 horas os bares sem isolamento acústico apropriado) ou se são 51 bares fechados após a uma hora da manhã (quando a lei manda fechar os bares sem segurança particular, estacionamento próprio e também isolamento acústico).

A maioria das intervenções do repórter neste início de diálogo ocorre, contudo, apenas por meio de marcadores conversacionais que denotam monitoramento do ouvinte. Os marcadores conversacionais são:

[...] elementos de variada natureza, estrutura, dimensão, complexidade semântico-sintática, aparentemente supérfluos ou até complicadores, mas de indiscutível significação e importância para qualquer análise de texto oral e para sua boa e cabal compreensão. [...] Os marcadores conversacionais são elementos que estruturam o texto, considerado não só como uma construção verbal cognitiva, mas também como uma organização interacional interpessoal. Ou seja, são recursos que sinalizam orientação ou alinhamento recíproco dos interlocutores ou destes em relação ao discurso. (URBANO, 2003, p. 93, 114)

No corpus selecionado, os marcadores são em sua maioria simples e não lexicalizados. Em 19 turnos do documentador, que deteve um total de 26 no trecho considerado, temos a presença solitária de sinais como hum, ahn, e ahn ahn.

Retomemos os elementos não lexicalizados do tipo ah, ahn, ahn ahn. Deve-se levar em conta que há os produzidos pelo falante (normalmente de formação simples, com ah) e outros, produzidos pelo ouvinte (normalmente compostos, como ahn ahn). Os marcadores do falante são freqüentemente preenchedores de pausas indicativas de hesitação ou momentos de planejamento textual. Os marcadores do ouvinte sinalizam a atenção, interesse, assentimento e/ou apoio do ouvinte ao falante, valendo como "estou entendendo; prossiga". São de grande ocorrência e recorrência e são conhecidos, de modo geral, como marcadores de monitoramento do ouvinte. (URBANO, 2003, p. 107, grifo do autor)

Os marcadores do falante presentes nesta entrevista são de teste de participação ou busca de apoio, do tipo né?, sabe? e certo?, que são "uma espécie de pergunta retórica, que abre expectativa de 'resposta', mas apenas no nível pragmático e dificilmente com implicações semânticas" (URBANO, 2003, p. 110). No texto analisado, de um total de 27 turnos do entrevistado, nada menos do que 13 têm um marcador de apoio, no caso, o né?.

Quadro 3:

No quesito turnos, aliás, a distribuição do corpus é como segue descrita no

QUADRO 2 - ESTATÍSTICAS DA ENTREVISTA

\begin{tabular}{|l|l|l|l|l|}
\hline Locutor & Número de turnos & $\%$ do total & $\begin{array}{l}\text { Palavras } \\
\text { faladas }\end{array}$ & $\%$ do total \\
\hline Entrevistador & 26 & 49 & 92 & 15,2 \\
\hline Entrevistado & 27 & 51 & 606 & 84,8 \\
\hline
\end{tabular}

Fonte: Pesquisa do autor.

Como podemos ver, apesar de ambos os interlocutores possuírem um número quase igual de turnos, é na duração e carga informativa desses turnos que a assimetria entre entrevistador e entrevistado se manifesta: enquanto o primeiro usa a palavra para perguntas pontuais e marcadores de monitoramento muito breves, o segundo usa seus 
turnos para tecer considerações a respeito do tópico, o que lhe rende tempo de fala e carga informativa muito superiores.

O debate sobre os tipos e papéis dos marcadores e o tempo de fala de cada um dos interlocutores é de fundamental importância para a análise da questão central deste estudo, a presença da audiência no discurso das partes. Isso porque os marcadores de monitoramento do ouvinte, neste caso, confirma a expectativa da fonte entrevistada de estar atendendo aos anseios da audiência - em tese, melhor delineada na mente do repórter, que lida diariamente com a presença virtual do público no jornal, do que pelo entrevistado, que é no máximo leitor e, logo, também parte do corpo abstrato audiência.

Assim, quando o repórter diz ahn ahn, é como se dissesse para a sua fonte "sim, você está falando o que a audiência quer ouvir, então prossiga nesse tópico, não se desvie dele". Por outro lado, quando o entrevistado emprega grande número de marcadores de busca de apoio, como o né?, está como que perguntando ao repórter "este tema realmente agrada à audiência? estou sendo claro? o nível lexical está adequado?". No contrato não-polêmico estabelecido pelo repórter ao longo da entrevista, interessa a ambas as partes cativar a audiência e mantê-la satisfeita.

As duas perguntas do entrevistador com vistas ao esclarecimento do já-dito também guardam nítida preocupação com a audiência - é por ela que a tarefa de deixar tudo muito claro se instaura. Assim, é importante, no discurso da entrevista, remover ambigüidades e procurar ser didático, assegurando o entendimento do público, que é heterogêneo e compreende desde especialistas em legislação municipal até jovens recém-saídos do ensino médio, com interesse no tema fechamento de bares, mas sem o menor conhecimento das cargas jurídica, política e social envolvidas nesse tópico. $\mathrm{O}$ próprio entrevistado também assume esse papel e procura ser didático:

12. Inf. porque veja bem são duas fiscalizações né? eu tenho uma fiscalização de barulho que é após as dez da noite...

13.Doc. $\quad$ ahã

14.Inf. e tem a questão dos Bares abertos que não têm condições de segurança tal após a uma da manhã são duas...

15.Doc. [

16.inf. duas legislações duas regulamentações que/

Ao dizer, na linha 12, "veja bem são duas fiscalizações", a fonte demonstra, especialmente pelo marcador "veja bem", que está interessada em transmitir de maneira clara as informações - não só para o entrevistador mas também para a audiência que será informada das palavras do entrevistado somente através do repórter/mídia em questão.

Se nos marcadores e na polidez (pela não-polemização da relação e respeito a regras básicas da conversação, como "fala um de cada vez") está subjacente a noção de audiência, em outros momentos do discurso ela aparece quase que explicitamente.

6.Inf. a partir de primeiro de agosto ele está funcionando de quinta a sábado das oito às cinco da manhã né? ... e a gente está deixando duas equipes de plantão e::: pra

7.Doc. $\quad($ ) ahn ahn

8.Inf. atender a::: porque o que ocorria - estou te falando isso em off depois você pergunta eu te falo em on pra você entender 
A parentética da linha 8 , "estou te falando isso em off depois você pergunta eu te falo em on pra você entender" demonstra explicitamente que há uma terceira-parte participando ainda que indiretamente, do evento discursivo. A preocupação do entrevistado, no caso, é que o que está sendo falado entre as linhas 18 e 20, nas quais ele critica o antigo sistema de funcionamento do Psiu (Programa Silêncio Urbano, responsável pela fiscalização de barulho na cidade de São Paulo) não chegue aos olhos e ouvidos do público. Por isso, fala em off, ou seja, fora da gravação, num diálogo eu-tu que não inclui, momentaneamente, a participação da audiência.

18.Inf. mas então mas voltando aqui ao problema do/ antigamente a pessoa fazia uma reclamação ... fazia:...... por exemplo ti/tinha um problema num bar à noite ela ia ligar no outro dia né ...

19.Doc. ahn ahn

20.Inf. pra fazer a reclamação aí seria agenDADO uma visita do Psiu né? ...

Por razões políticas ou pessoais, o fato é que o entrevistado não gostaria que o público soubesse que ele mesmo desaprova o antigo sistema de funcionamento do programa que coordena, o Psiu.

Nessa mesma linha 18 temos outra manifestação da presença da audiência no discurso: ao dizer "mas então voltando aqui ao problema do/", o entrevistado nitidamente está se autopoliciando para não fugir ao tópico proposto. É interessante notar que, mesmo sem a intervenção do entrevistador - que é quem domina o papel social de repórter, ou seja, quem propõe e estimula o desenvolvimento ou encerramento dos tópicos abordados na entrevista - o entrevistado reorienta o discurso da maneira que contratualmente julga mais adequada, retornando ao que interessa (supostamente) à audiência.

Em outro turno do informante aparece clara a consciência idéia de que o discurso da entrevista é destinado a um uso público, e não privado:

23.Doc. e agora é na hora a verificação?

24.Inf. agora... veja bem agora dentro das possibilidades que a gente tem pouca estrutura...

25.Doc. $\quad$ certo

26.Inf. por exemplo a gente está fazendo cerca de dez... dez... va/vamos chamar assim de intervenção online ... que é uma pessoa reclama aí na HOra a equipe também a gente...

$\mathrm{Na}$ linha 24, o atenuador "agora dentro das possibilidades" mostra que o entrevistado tem consciência de que, sendo destinado a um uso público, seu discurso será incoerente, já que - pressupõe-se - o público sabe ou infere que a ação dos fiscais da Prefeitura contra estabelecimentos barulhentos não é feita na hora em que acontece a denúncia. A saída discursiva encontrada, "dentro das possibilidades", preserva a face da instituição e ao mesmo tempo tenta ser eufórica, mostrar que, salvo infortúnios cujo controle escaparia à administração municipal, o trabalho do órgão é eficiente.

Já na linha 26 desse mesmo trecho, a passagem "va/vamos chamar assim de intervenção on line" também revela preocupação com a publicidade do discurso. Fica claro que o entrevistado quer passar um conceito de modernidade ao designar sua ação 
como online - que não é como funciona a ação empírica, mas sim como deve ser conhecida entre o público receptor da entrevista.

Para encerrar esta análise, salientamos que o mesmo fenômeno ocorre nas últimas linhas do corpus (46-53), nas quais o entrevistado tenta preservar a face sua e da instituição à qual pertence (grifo nosso):

46.Inf. agora tem uma coisa aí que é estrutural que é o seguinte principalmente na questão aí do que abre depois da uma... esse problema só vai ser 47.Doc. $\quad$ ahn ahn 48.Inf. porque hoje um grande problema na prefeitura é o seguinte você tem fiscais para $\mathbf{N}$ coisas né?

49.Doc. $\quad$ ahn ahn

50.Inf. quan/quando toda a fiscalização estiver a partir do ano que vem nas subprefeituras... você vai ter um... volume... uma equipe de fiscais muito maior.... para poder... atender porque você pega o bar que está... após uma hora, boa parte desses bares não vai ter alvará... então é um fiscal pra alvará um fiscal pro barulho

51.Doc. $\quad$ ahn ahn

52.Inf. um fiscal pra não sei o que um fiscal pra depois da uma hora então você tendo uma fiscalização que fiscaliza todo esse tipo de serviço da prefeitura todo esse tipo de irregularidade da cidade você melhora muito o potencial de atendimento você imagine o seguinte são 80 mil bares em São Paulo

53.Doc. $\quad$ ahn ahn (...)

Como podemos ver, em 46 o informante reconhece que há um problema - pois a audiência sabe que há - e, depois de ter reforçado que no passado era pior, aponta para a solução - que a audiência espera e cobra. Em 48, introduz a retórica da falta de pessoal e culpa a burocracia legal - como precisa haver um fiscal para cada tipo de atividade, $o$ trabalho é demorado e falho. Em 50 e 51, encerra tal raciocínio acrescentando que a solução está a caminho, virá "a partir do ano que vem", com a descentralização do trabalho do Psiu. Finalmente, reitera que em uma cidade do porte de São Paulo, que abriga "80 mil bares" esses problemas são muito difíceis de resolver. Novamente, livra de culpa a Prefeitura, pois, segundo essa linha de pensamento, a cidade é tão grande que seria impossível fiscalizá-la adequadamente de modo a satisfazer a totalidade da população - ou, no mínimo, os leitores da Folha de S.Paulo, veículo para o qual foi concedida a entrevista.

\section{Considerações finais}

Conforme queríamos demonstrar com exemplos de uma situação real de entrevista jornalística, vimos que esse tipo de interação, mesmo quando realizada entre apenas dois agentes presenciais, necessariamente inclui uma terceira parte capaz de influenciar e de (re)direcionar o discurso, a audiência.

Ainda que não se manifeste diretamente durante o evento comunicativo, a audiência está subjacente ao discurso e aparece na seleção lexical empregada por entrevistador e entrevistado, na escolha e reorientação dos tópicos conversacionais, na definição de um clima contratual ou polêmico de condução do evento e na necessidade latente de preservação da face dos interagentes. $\mathrm{O}$ fato de as entrevistas se destinarem a 
um uso público - diferentemente de conversações espontâneas, nas quais os laços interacionais do tipo $e u$-tu e o tom intimista de condução da narrativa são mais sólidos acentua a preocupação com a preservação da imagem e com a clareza do discurso (na entrevista, ambigüidades não são, geralmente, bem-vindas) dos falantes.

Conforme analisamos, a preocupação com o público - entidade, ressalte-se, abstrata, genericamente delineada por meio de múltiplas inferências - não é significativamente maior no entrevistador/repórter do que no entrevistado/fonte. Mesmo mais distante do dia-a-dia de uma redação de jornal e, logo, das manifestações do público leitor, o entrevistado - que também se torna audiência ao ler o jornal - tem similar ou maior nível de preocupação, já que é sobretudo a sua face (e da instituição que representa) que será exposta pela entrevista. Além disso, cabe a ele também ultrapassar sem maiores ruídos a barreira do agente mediador - o repórter - para fazer sua mensagem chegar, com o mínimo de interferência possível, ao público visado.

Também do ponto de vista da Análise da Conversação, vimos que essas estratégias para prever e satisfazer o público se manifestam freqüentemente pelo uso reiterado de marcadores conversacionais - o ouvinte faz o monitoramento e incentiva $o$ desenvolvimento do tópico, enquanto o falante testa a participação do ouvinte e busca seu apoio por meio de perguntas retóricas do tipo não é? Outros aspectos que futuramente podem ser abordados sobre essa questão - já que não é nossa intenção esgotar o tema em estudo tão breve - são os alongamentos, hesitações e pausas na fala do entrevistado, que escolhe as palavras e encadeia raciocínios de forma a conduzira audiência conforme a sua vontade.

A análise estatística do corpus confirmou também o fato de as entrevistas serem interações essencialmente assimétricas: enquanto $84,8 \%$ do discurso está no turno do entrevistado, que é quem mais se delonga na divulgação de suas idéias, o entrevistador utilizou os $15,2 \%$ restantes para lançar perguntas pontuais - de esclarecimento ou confirmação das informações prestadas - e, principalmente, demonstrar apoio ao falante com marcadores não lexicalizados do tipo ahn ahn. Apesar dos turnos mais breves e menos informativos, coube a ele, repórter, iniciar, conduzir e, finalmente, encerrar a interação.

\section{Referências}

FÁVERO, Leonor Lopes. A entrevista na fala e na escrita. In: PRETI, Dino (Org.). Fala e escrita em questão. São Paulo: Humanitas; FFLCH/USP, 2000. p. 79-97.

FÁVERO, Leonor Lopes; ANDRADE, Maria Lúcia da Cunha Victorio de Oliveira. Os processos de representação da imagem pública nas entrevistas. In: PRETI, Dino (Org.). Estudos de língua falada: variações e confrontos. São Paulo: Humanitas; FFLCH/USP, 1998. p. 153-178.

; AQUINO, Zilda Gaspar O. A dinâmica das interações verbais: o trílogo. In:

PRETI, Dino (Org.). Interação na fala e na escrita. São Paulo: Humanitas; FFLCH/USP, 2002. p. 159-177.

HILGERT, José Gastão. A colaboração do ouvinte na construção do enunciado do falante - um caso de interação intraturno. In: PRETI, Dino (Org.). Interação na fala e na escrita. São Paulo: Humanitas; FFLCH/USP, 2002. p. 89-124.

MARCUSCHI, Luiz Antônio. Análise da conversação. São Paulo: Ática, 2001.

Da fala para a escrita - atividades de retextualização. São Paulo: Cortez, 2003.

RODRIGUES, Ângela C. Souza. Língua falada e língua escrita. In: PRETI, Dino (Org.). Análise de textos orais. 6. ed. São Paulo: Humanitas; FFLCH/USP, 2003. p. 15-38. 
URBANO, Hudinilson. Marcadores conversacionais. In: PRETI, Dino (Org.). Análise de textos orais. 6. ed. São Paulo: Humanitas; FFLCH/USP, 2003. p. 93-116.

\section{Anexo A}

Data: $12 / 10 / 04$

Local do inquérito: Folha de S.Paulo (documentador), Prefeitura de São Paulo (locutor) Tipo de inquérito: Gravação telefônica de entrevista formal

Tema: 'Lei seca' de fechamento de bares após $1 \mathrm{~h}$

Documentador (Doc): Renato Essenfelder

Duração total: 25 minutos

Informante (Inf): VG, masculino, paulistano, secretário municipal, intimidade nula com o documentador

1. Doc. - (...) sobre as blitze para fechamento de bares após a uma hora... o/ eu queria saber o andamento se/se vai ser retomado isso agora com mais força...

2. Informante - Olha continua tendo o que está tendo agora::

3. Doc. hum?

4. Inf. é que a gente deu uma modernizada no Psiu né? porque o Psiu não funcionava após as seis da tarde né?

5. Doc. ahã

6. Inf. a partir de primeiro de agosto ele está funcionando de quinta a sábado das oito às cinco da manhã né? ... e a gente está deixando duas equipes de plantão e::: pra

7. Doc. ( ) ahn ahn

8. Inf. atender a::: porque o que ocorria - estou te falando isso em off depois você pergunta eu te falo em on pra você entender

9. Doc. ahã

10. Inf. o... o que ocorria no::.... no passado né? a pessoa tinha um bAR uma reclamação de barulho ...

11. Doc. ahn ahn

12. Inf. porque veja bem são duas fiscalizações né? eu tenho uma fiscalização de barulho que é após as dez da noite...

13. Doc. ahã

14. Inf. e tem a questão dos Bares abertos que não têm condições de segurança tal após a uma da manhã são duas...

15. Doc. isso

16. Inf. duas legislações duas regulamentações que/

17. Doc.

18. Inf. mas então mas voltando aqui ao problema do/ antigamente a pessoa fazia uma reclamação ... fazia::.... por exemplo ti/tinha um problema num bar à noite ela ia ligar no outro dia né ...

19. Doc. ahn ahn

20. Inf. pra fazer a reclamação aí seria agenDADO uma visita do Psiu né? ...

21. Doc. ahn ahn 
22. Inf. o que que a gente implantou a partir do primeiro de agosto? o telefone funciona de quinta a sábado 24 horas ... com isso e colocou duas equipes de plantão então se tem uma reclamação de um bar tal a equipe vai e vai verificar ...

23. Doc. e agora é na hora a verificação?

24. Inf. agora... veja bem agora dentro das possibilidades que a gente tem pouca estrutura...

25. Doc. certo

26. Inf. por exemplo a gente tá fazendo cerca de dez... dez... va/vamos chamar assim de intervenção online ... que é uma pessoa reclama aí na HOra a equipe também a gente...

27. Doc.

dez por noite isso?

28. Inf. dez por noite nesse caso que eu to te falando

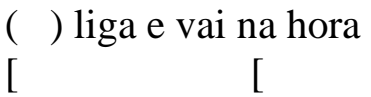

Ahã ahã

29. Doc

e também a gente está agora ( ) com o rádio a gente tem sete equipes que saem toda noite né?..

31. Doc. ahn ahn

32. Inf. então a gente colocou o rádio tá todo mundo com rádio e a gente também se as equipes estiverem nas imediações de uma reclamação elas vão e atendem na hora

33. Doc. ahn ahn

34. Inf. então isso foi uma das primeiras coisas que foram feitas... a segunda coisa... foi uma coisa que nós combinamos junto com a secretaria de segurança pública do estado o comando geral da PM e a guarda municipal...

35. Doc. ahn ahn

36. Inf. é ter uma política NAS sete equipes restantes de prioridade NA periferia...

37. Doc. ahn ahn

38. Inf. pra::.... interferir intervir na questão do fechamento após a uma hora né?...

39. Doc. ce::rto

40. Inf. então pra você ter uma idéia nas últimas duas semanas ... a gente fechou 51 bares né? ...

41. Doc. ahn ahn

42. Inf. nos últimos dois fins de semana

43. Doc. então somando aí os que abrem depois da uma e os de barulho... esses... esse número não?

44. Inf. os que abrem depois da uma né? ...

45. Doc. ah, certo

46. Inf. agora tem uma coisa aí que é estrutural que é o seguinte principalmente na questão aí do que abre depois da uma... esse problema só vai ser resolvido quando tiver toda a fiscalização nas subprefeituras né? ...

47. Doc. ahn ahn

48. Inf. porque hoje um grande problema na prefeitura é o seguinte você tem fiscais para $\mathrm{N}$ coisas né?

49. Doc. ahn ahn

50. Inf. quan/quando toda a fiscalização estiver a partir do ano que vem nas subprefeituras... você vai ter um... volume... uma equipe de fiscais muito maior.... para poder... atender porque você pega o bar que tá... após uma hora, boa parte desses bares não vai ter alvará... então é um fiscal pra alvará um fiscal pro barulho

51. Doc. ahn ahn 
52. Inf. um fiscal pra não sei o que um fiscal pra depois da uma hora então você tendo uma fiscalização que fiscaliza todo esse tipo de serviço da prefeitura todo esse tipo de irregularidade da cidade você melhora muito o potencial de atendimento você imagine o seguinte são 80 mil bares em São Paulo

53. Doc. ahn ahn (...)

\section{Anexo B}

NORMAS PARA TRANSCRIÇÃO (PROJETO NURC-SP)

\begin{tabular}{|c|c|c|}
\hline OCORRÊNCIAS & SINAIS & EXEMPLIFICAÇÃO \\
\hline $\begin{array}{l}\text { Incompreensão de palavras e } \\
\text { segmentos }\end{array}$ & ( ) & $\begin{array}{l}\text { Do nível de renda... ( ) nível } \\
\text { de renda nominal... }\end{array}$ \\
\hline Hipótese do que se ouviu & (hipótese) & $\begin{array}{l}\text { (estou) meio preocupado } \\
\text { (com o gravador) }\end{array}$ \\
\hline $\begin{array}{l}\text { Truncamento (havendo } \\
\text { homografia, usa-se acento } \\
\text { indicativo da tônica e/ou } \\
\text { timbre) }\end{array}$ & / & e comé/ e reinicia \\
\hline Entonação enfática & Maiúscula & $\begin{array}{l}\text { porque as pessoas reTÊM } \\
\text { moeda }\end{array}$ \\
\hline $\begin{array}{l}\text { Prolongamento de vogal e } \\
\text { consoante (como s, r) }\end{array}$ & $\begin{array}{l}:: \text { podendo aumentar para :::: } \\
\text { ou mais }\end{array}$ & $\begin{array}{l}\text { Ao emprestarem os... éh ::: ... } \\
\text { o dinheiro }\end{array}$ \\
\hline Silabação & - & por motivo tran-sa-ção \\
\hline Interrogação & $?$ & e o Banco... Central... certo? \\
\hline Qualquer pausa & $\ldots$ & $\begin{array}{l}\text { São três motivos... ou três } \\
\text { razões... que fazem com que } \\
\text { se retenha moeda... existe } \\
\text { uma... retenção }\end{array}$ \\
\hline $\begin{array}{l}\text { Comentários descritivos do } \\
\text { transcritor }\end{array}$ & ((minúscula) $)$ & $(($ tossiu $))$ \\
\hline $\begin{array}{l}\text { Comentários que quebram a } \\
\text { seqüência temática da } \\
\text { exposição, desvio temático }\end{array}$ & $-\ldots$ & $\begin{array}{l}\text {... a demanda de moeda - - } \\
\text { vamos dar essa notação - - } \\
\text { demanda de moeda por } \\
\text { motivo }\end{array}$ \\
\hline $\begin{array}{l}\text { Superposição, } \\
\text { simultaneidade de vozes }\end{array}$ & {$\left[\begin{array}{l}\text { Ligando as } \\
\text { linhas }\end{array}\right.$} & $\begin{array}{l}\text { A. na }[\text { casa da sua irmã } \\
\text { B. }{ }^{2} \text { sexta feira? } \\
\text { A. fizeram }{ }^{\text {lá... }} \\
\text { B. } \quad \text { cozinharam lá? }\end{array}$ \\
\hline $\begin{array}{l}\text { Indicação de que a fala foi } \\
\text { tomada ou interrompida em } \\
\text { determinado ponto. Não no } \\
\text { seu início, por exemplo. }\end{array}$ & $(\ldots)$ & (...) nós vimos que existem... \\
\hline $\begin{array}{l}\text { Citações literais ou leituras } \\
\text { de textos, durante a gravação }\end{array}$ & “ “ & $\begin{array}{l}\text { Pedro Lima... ah escreve na } \\
\text { ocasião... "O cinema falado } \\
\text { em língua estrangeira não } \\
\text { precisa de nenhuma } \\
\text { baRREIra entre nós"... }\end{array}$ \\
\hline
\end{tabular}


Fonte: PRETI, Dino. Análise de textos orais. São Paulo: Humanitas; FFLCH/USP, 2003. p. 13-14.

\begin{abstract}
Placed somewhere in the continuum between the written and spoken modalities of the language, the interview, in its different types, is a special sort of interaction, in which the publicity of the speech (caused by its massive circulation) substitutes the "privacy" idea commonly associated to dialogues. Because of that, the speakers at interviews need to be worried about questions like face's preservation in front of an absent public and the attendance of generic hearing's expectations. This study shows, based on a real journalistic interview, what strategies both interviewed and interviewer uses to conduct its speeches in order to satisfy the generic public.
\end{abstract}

Key words: Analysis of conversation; dialogue; interaction. 